\title{
Anomalias na precipitação de quatro municípios do Amazonas, Brasil
}

\author{
Anomalies in the precipitation of four municipalities of the Amazonas, Brazil \\ Anomalías en la precipitación de cuatro municipios en Amazonas, Brasil
}

\section{Resumo}

Os fenômenos climáticos El Niño e La Niña atualmente recebem mais atenção devido ao fato de seus acontecimentos ocorrerem com maior frequência influenciando o clima regional e global. Na metodologia analisaram-se cálculos estatísticos de dados no período histórico de 1985 a 2016, identificando as variações divergentes da média calculada encontrando assim as anomalias dos regimes pluviométricos, correlacionando com anos de registros dos eventos climáticos El Niño e La Niña foram identificadas anomalias climáticas de grande impacto nos municípios de Manaus, Itacoatiara, Eirunepé e São Gabriel da Cachoeira, motivo este que o cidadão e a indústria deve-se atentar para o registro de tais eventos, pois os regimes pluviométricos influenciam desde produção de alimento a geração de energia, enchentes ou secas dos rios do Amazonas.

Palavras-chave: Precipitação; El Niño; La Niña.

\begin{abstract}
The El Niño and La Niña climate phenomena currently receive more attention due to the fact that their events occur more frequently influencing the regional and global climate. In the methodology analyzed statistical calculations of data in the historical period from 1985 to 2016, identifying the divergent variations from the calculated average thus finding the anomalies of rainfall regimes, correlating with years of records of El Niño and La Niña climate events were identified climate anomalies of great impact in the municipalities of Manaus, Itacoatiara, Eirunepé and São Gabriel da Cachoeira, which is why the citizen and the industry should pay attention to the registration of such events, because the rainfall patterns influence from production of food to power generation, floods or droughts of the rivers of the Amazon.
\end{abstract}

Keywords: Precipitation; El Niño; La Niña.

\section{Resumen}

Los fenómenos climáticos de El Niño y La Niña reciben actualmente más atención debido a que sus eventos ocurren con mayor frecuencia influyendo en el clima regional y global. En la metodología se analizaron los cálculos estadísticos de los datos en el período histórico de 1985 a 2016, identificando las variaciones divergentes de la media calculada encontrar así las anomalías de los regímenes pluviométricos, correlacionando con los años de registros de los eventos climáticos de El Niño y La Niña se identificaron anomalías climáticas de gran impacto en los municipios de Manaus, Itacoatiara, Eirunepé y São Gabriel da Cachoeira, por lo que el ciudadano y la industria deben prestar atención al registro de tales eventos, ya que los patrones de lluvia influyen desde la producción de alimentos hasta la generación de energía, las inundaciones o sequías de los ríos de la Amazonía.

Palabras clave: Precipitación; El Niño; La Niña. 


\section{Introdução}

A circulação geral da atmosfera alimentada pela movimentação do ar, influenciada diretamente pela circulação permanente da atmosfera e pela redistribuição de energia solar, determinam as zonas climáticas e os tipos de clima em diferentes locais do planeta (Mendonça \& Danni-oliveira, 2007). Na América do Sul a precipitação é induzida por vários tipos e diferentes intensidades de sistemas, tanto em escala de variabilidade sazonal como interanual, a nível de variabilidade sazonal temos como por exemplo, os Jatos de Baixos Níveis, a Zona de Convergência Intertropical, Zona de Convergência do Atlântico Sul, Alto da Bolívia etc. Inicialmente é importante ressaltar que sistemas frontais são responsáveis por perturbações na atmosfera e são ativos quase ano todo, por consequência disto ocasionam mudança na precipitação e temperatura em todo território da América do Sul, caracterizado por uma frente fria e outra quente, os sistemas frontais influenciam no Brasil de forma significativa não somente nas regiões sul e sudestes, mas também parte sul da região nordeste e nas chuvas de inverno no norte do país (Britto \& Saraiva, 2001; Dorneles, et al., 2020 ).

Similarmente um outro agente gerador de chuvas, conhecido como jato de baixos níveis, é responsável pelo transporte de umidade do leste da cordilheira dos Andes desde a região amazônica em direção a bacia do Prata. Além de fundamental importância para meteorologia, pode ser identificado através de perfis de vento desempenhando um papel importante para o ciclo hidrológico da região (Santos, et al.,2008). As alterações no padrão de vento também estão associados as estações chuvosas e seca, como mencionaram os autores Vargas e Veiga (2017), na qual identificaram que devido um pico de estação chuvosa ocorrido no leste da Bolívia em 2005, foi observado que no estado do Amazonas os ventos provenientes do Nordeste divergiram para Atlântico Norte, resultando na redução do fluxo de umidade e por consequência no enfraquecimento dos jatos de baixos níveis. Assim como no Amazonas, Albuquerque, et al., (2010) mencionam que na cidade de Belém sua estação chuvosa tende a durar de cinco a seis meses, com característica de pancadas de chuvas e isoladas, em muitos casos procedente pela intensificação de efeitos locais como a zona de convergência intertropical.

No estado do Amazonas existe uma diferença no regime de precipitação, devido a localidade dos municípios em diferentes longitudes/latitudes, assim como o alto nível de evapotranspiração decorrentes das florestas, esses fenômenos são presenciados com maior intensidade principalmente em anos de El Niño e La Niña. É importante compreender que alguns elementos climáticos são imensamente afetados pelos fenômenos climáticos que por consequência influenciam no desenvolvimento de várias atividades humanas, atividade econômicas e na agricultura (Mendonça \& Danni-oliveira, 2007). Podemos ressaltar que os impactos oriundos dos fenômenos El Niño e La Niña ocorrem em todas as regiões do Brasil. Observamos que a precipitação pluviométrica é maior ou menor do que os anos neutros, notório principalmente nas regiões do norte, nordeste, e sudeste apresentando uma variação entre secas ou grande volume de chuva (De Oliveira \& Saraiva, 2018).

O fenômeno El Niño - Oscilação Sul (ENOS) é um sistema acoplado oceano-atmosfera sobre pacífico tropical, definido por variações na TSM e pressão atmosférica. O El Niño é o fenômeno ENOS (El Niño - Oscilação Sul) que representa o aquecimento da temperatura da superfície do mar (TSM) que é caracterizado por anomalias positivas e inibe a formação de nuvens convectivas, na região do pacífico Equatorial, entre a costa do Peru e da Austrália. A La Niña representa o resfriamento da temperatura anômala das águas, caracterizada por anomalias negativas e provoca a formação de nuvens convectivas (Andreoli \& Kayano, 2007). Os eventos El Niño e La Niña tendem a se alternar entre 3 a 7 anos e seus intervalos podem mudar de 1 a 10 anos, no entanto devido a ações antrópicos e por consequência a mudanças climáticas os eventos tornaram-se cada vez mais frequentes, ressaltando que tanto o aquecimento como o resfriamento do oceano pacifico provocam alteração na circulação do vento, assim como nos padrões de umidade e logo nas variações de chuvas, principalmente em regiões tropicais (Cptec, 2021). Através da anomalia climática observarmos a alteração extrema de um elemento em uma quantidade de fatos climatológicos com desvios notáveis do padrão observado da instabilidade (Pereira, et al., 2002). 
Apesar da limitação dos dados de superfície no estado do Amazonas, o estudo da variabilidade da precipitação associado com influência do El Niño e La Niña, é de fundamental importância na manutenção do ciclo regional da água, pois todo ciclo depende da água precipitada, que tem como função equilíbrio térmico do planeta, além de fornecer água potável para seres vivos, auxilia nas atividades humanas como, agropecuária, pesca, comércio, transporte etc.

No entanto devido à extensão territorial do estado Amazonas, isso se torna uma dificuldade, pois os dados de séries históricas nem sempre estão disponíveis de forma completa sendo a opção de recorrer à dados extraídos de órgãos governamentais (Carvalho \& Da Silva, 2006; Vianello \& Alves, 2012). Diante disso o presente artigo teve como objetivo avaliar as anomalias do regime pluviométrico de quatro municípios do estado do Amazonas (Manaus, Itacoatiara, Eirunepé e São Gabriel da Cachoeira) e em seguida correlacionar com os anos de registros de El Niño e La Niña na série histórica de 1985 a 2016.

\section{Metodologia}

O estado do Amazonas está localizado em uma região equatorial, de clima quente úmido, possui uma área de 1.559.167,878 km² com uma população estimada em 4.269.995 pessoas sendo a capital Manaus (Ibge,2021). É característico da região Amazônica apresentar dois períodos bastante definidos, sendo ele o período de chuvas que corresponde entre os meses de novembro e março (Figura 1), e o período de seca que abrange os meses de maio a setembro (Figura 2), sendo os meses de abril e outubro considerado períodos de transição (Fish, et al., 1998; Júnior, et al., 2018).

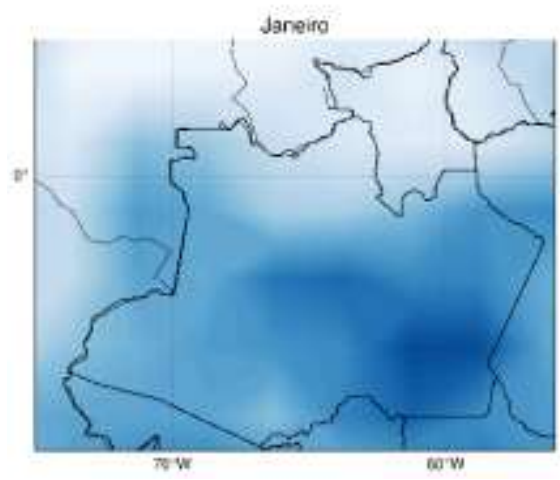

a'w

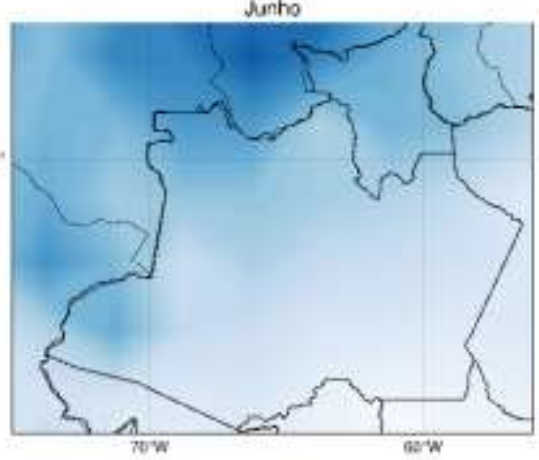

Figura 1. Trimestre JFM de precipitação.

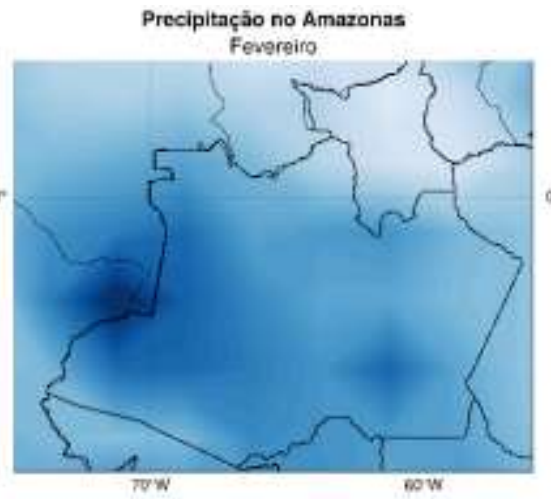

Fonte: Autores (2021).

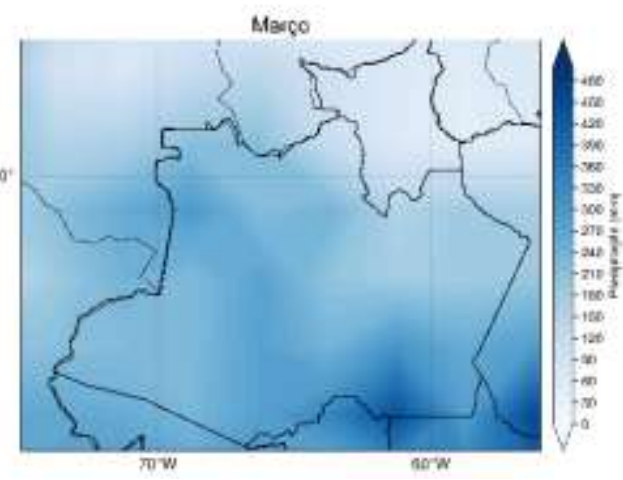

${ }^{90} \mathrm{~W} / \mathrm{W}$

Figura 2. Trimestre JJA de precipitação.
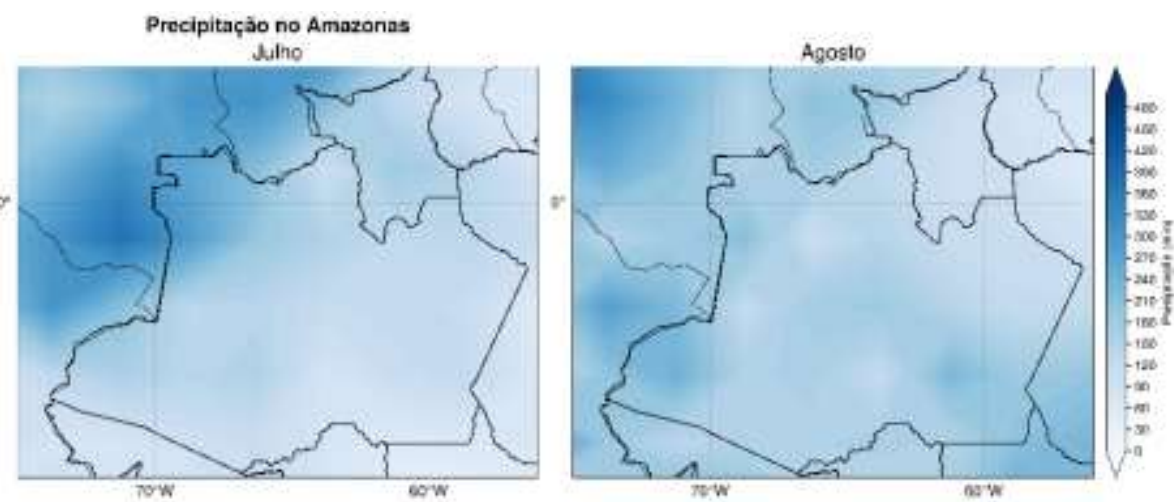

Fonte: Autores (2021). 
As séries históricas de médias mensais de precipitação foram obtidas nos bancos de dados meteorológicos (BMEP) do Instituto Nacional de Meteorologia - INMET. Os dados disponibilizados pelo INMET, são obtidos através de estações meteorológicas automáticas e convencionais, que passaram por um rigoroso controle de qualidade antes de serem disponibilizados para que possam ser usados pela comunidade em geral. A partir da obtenção dos dados, foi analisado o período de 1985 a 2016, viabilizando melhor distribuição espacial. Para imagens espaciais foi utilizado a série de precipitação total mensal é disponibilizada pela Global Precipitation Climatology Centre para o período de 1981 a 2016, a partir dos seus produtos na V2018. Esse conjunto de dados é compilado de várias estações atualizadas e contém totais mensais na grade global de 0,5 graus de latitude x 0,5 graus de longitude. Para os dados do INMET de precipitação pluvial em primeiro momento foram agrupados os dados de mês a mês do período analisado, em seguida calcularam-se os valores médios desses períodos para obter uma tendência central, para melhor identificar as anomalias foi utilizado o cálculo de anomalia, baseado na climatologia do período de 1985-2016, e assim correlacionando com os anos de registros de El Niño e La Niña mais intensos.

Para anomalia utilizou-se: AN = (valor observado - média climatológica)

Os anos de ocorrência de El Niño e La Niña obtidas na tabela disponibilizada pela NASA/National Weather Serviceclimate prediction center - NOAA (Figura 3). Com base nessa figura, verifica-se durante um período de 100 anos quais os anos em que ocorreram os eventos quentes (El Niño) e eventos frios (La Niña) do El Niño Oscilação Sul (ENSO).

Figura 3. Anos de Registro de El Niño, Neutro e La Niña.

\begin{tabular}{|c|c|c|c|c|c|c|}
\hline \multicolumn{5}{|c|}{ El Niño - 26 } & \multicolumn{3}{c|}{ La Niña - 23 } \\
\hline Weak-11 & Moderate - 7 & Strong - 5 & Very Strong - 3 & Weak - 11 & Moderate - 5 & Strong - 7 \\
\hline $1952-53$ & $1951-52$ & $1957-58$ & $1982-83$ & $1954-55$ & $1955-56$ & $1973-74$ \\
$1953-54$ & $1963-64$ & $1965-66$ & $1997-98$ & $1964-65$ & $1970-71$ & $1975-76$ \\
$1958-59$ & $1968-69$ & $1972-73$ & $2015-16$ & $1971-72$ & $1995-96$ & $1988-89$ \\
$1969-70$ & $1986-87$ & $1987-88$ & & $1974-75$ & $2011-12$ & $1998-99$ \\
$1976-77$ & $1994-95$ & $1991-92$ & & $1983-84$ & $2020-21$ & $1999-00$ \\
$1977-78$ & $2002-03$ & & & $1984-85$ & & $2007-08$ \\
$1979-80$ & $2009-10$ & & & $2000-01$ & & $2010-11$ \\
$2004-05$ & & & & $2005-06$ & & \\
$2006-07$ & & & & $2008-09$ & & \\
$2014-15$ & & & & $2016-17$ & & \\
$2018-19$ & & & & $2017-18$ & & \\
\hline
\end{tabular}

Fonte: GGWEATHER (2021).

\section{Resultados e Discussão}

De acordo com Reboita, et al., (2012), a região mais chuvosa da América do Sul localiza-se na parte da bacia Amazônica, onde sua média de precipitação é superior a $2450 \mathrm{~mm} / \mathrm{ano}$. O estado do Amazonas com suas estações de seca e úmida bastante definida apresentam uma alta precipitação principalmente durante verão austral amazônico (Junior, et al., 2018). Observamos na Figura 4, a série histórica de 1981-2016 da variabilidade de precipitação para todo estado do Amazonas, onde suas máximas ultrapassam $275 \mathrm{~mm}$, como também, valores abaixo de $40 \mathrm{~mm}$.

A variabilidade na precipitação influencia diretamente na dinâmica fluviais dos rios da Amazônia em períodos chuvosos provocando as cheias e a diminuição das chuvas acarreta na vazante, ambos apresentando-se em intervalos diferentes (Aleixo \& Neto, 2019). Vale ressaltar que os eventos influenciam em outros elementos climáticos, já que os desvios positivos e negativos da precipitação também controlam as anomalias da temperatura do ar (Oliveira, et al., 2006). 
Figura 4. Variabilidade de precipitação no Amazonas

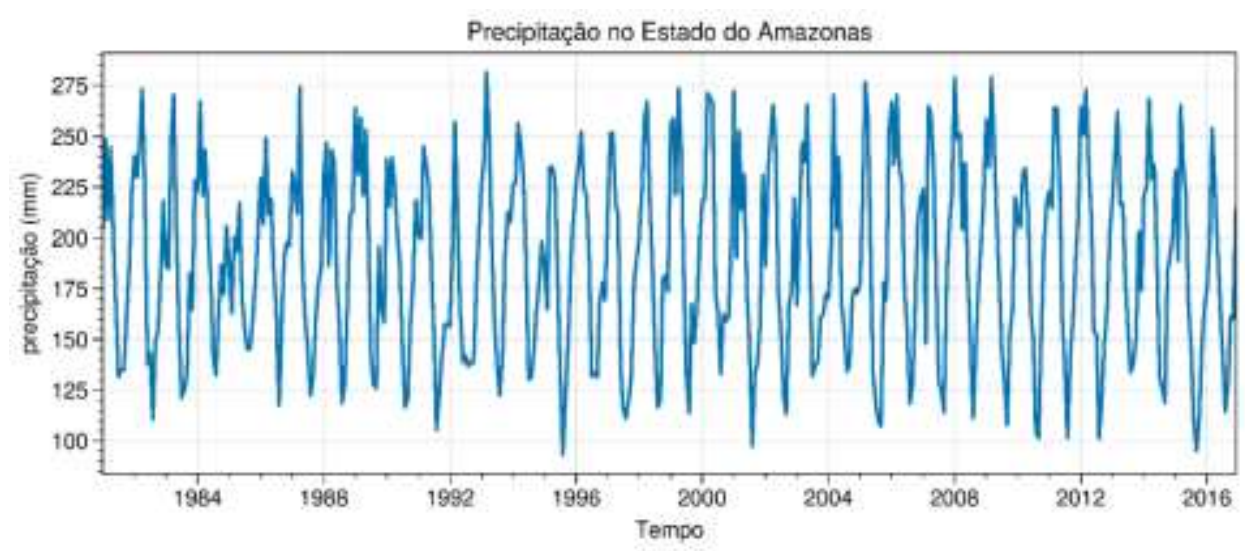

Fonte: Autores (2021).

O estuda da variabilidade da precipitação, em muitos casos, estão associados a sistemas de acoplamento oceano atmosférico, como por exemplo El Niño Oscilação Sul (Welter, 2018; De Moraes Dias, et al., 2020). Para os municípios dos estados do Amazonas, verificamos essa influência nas anomalias de precipitação durante os eventos de El Niño e La Niña. Após selecionarmos os eventos de El Niño mais intensos (figura 3), verificou-se que dentre o período de estudo os anos selecionados o ENSOS na sua fase quente mostrou maior intensidade nos anos de 1991-1992, 1997-1998, $2015-2016$.

Foi identificado nos munícipios de Manaus, Itacoatiara, Eirunepé e São Gabriel da Cachoeira para o ano de 1991/1992 (Figura 5) a predominância deste evento em suas anomalias de precipitação, provocando uma significativa redução nas chuvas. Observamos que na cidade de Manaus essa diminuição nas chuvas ocorreu entre os meses de agosto/1991 a novembro/1991 com suas precipitações abaixo da média histórica assim como junho/1992 a novembro/1992. No entanto observamos que a cidade com mais impacto pela presença do evento de El Niño foi o de Eirunepé, na qual suas precipitações foram abaixo da média em quase todo período de estudo. No mês de setembro/1991 foi constatado uma anomalia de $-143,24$ mm. Já em Itacoatiara a maior redução abaixo da média foi de 213,73 mm em dezembro/1991 e em São Gabriel da Cachoeira 228,81 mm abaixo da média em novembro/1991, logo analisamos que evento climático teve maior impacto no ano de 1991.

Figura 5. Anomalia da Precipitação em ano de El Niño 1991/1992.

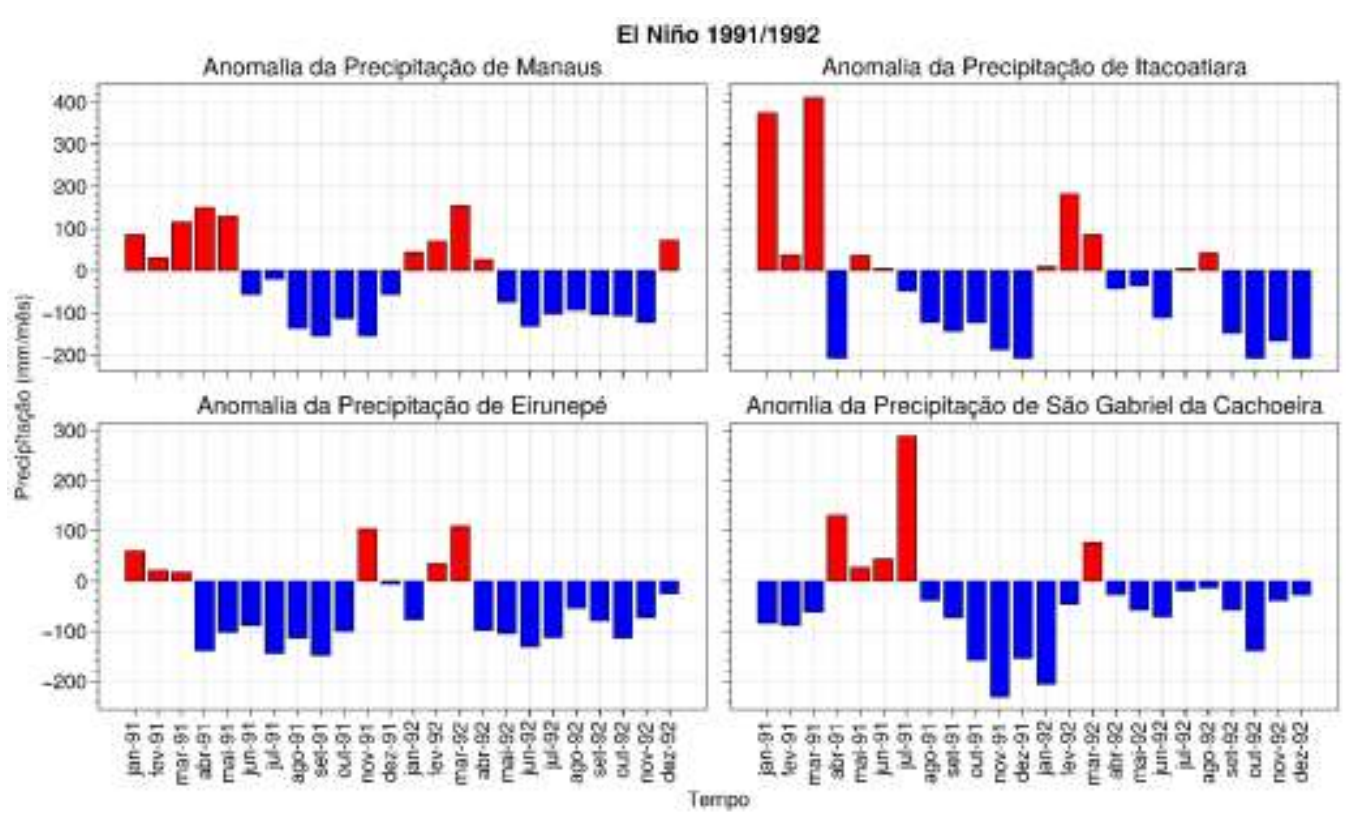

Fonte: Autores (2021). 
Consideramos que para o ano de El Niño 1997/1998 (figura 6) identificamos pouca variabilidade nas anomalias de precipitação em alguns municípios, sendo alguns meses específicos com valores extremamente distantes da média da série histórica, como por exemplo, em Manaus em julho/1997 um valor de $-195 \mathrm{~mm}$ e assim com o passar dos meses um leve aumento na precipitação e reduzindo novamente. Para Itacoatiara entre junho/1997 a outubro/1997 verificamos essa redução das chuvas e ocorrendo novamente no mesmo período do ano seguinte. Um evento climático extremo de seca para região amazônica provoca em sua grande parte a redução dos afluentes do rio Amazonas, fazendo com que populações residentes nos interiores do estado que em muitos casos sobrevivem do sistema pesqueiro acabam enfrentando dificuldades e se deslocam até a capital em busca de uma qualidade de vida ambiental melhor (De Oliveira, et al., 2019).

Figura 6. Anomalia da Precipitação em ano de El Niño 1997/1998.

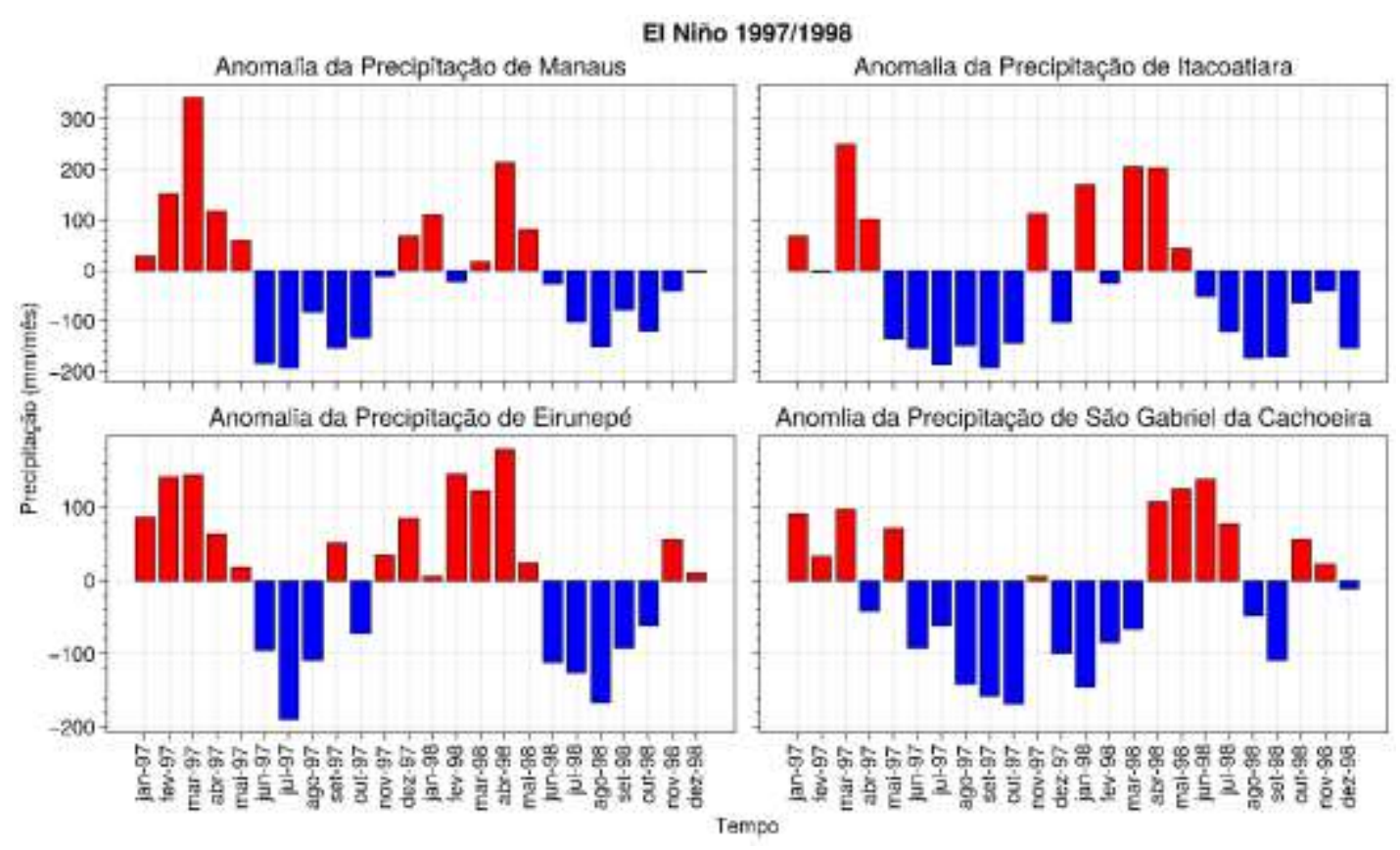

Fonte: Autores (2021).

De acordo com a NASA no ano 2015-2016 ocorreu um evento de anomalia climática de maior intensidade, o fenômeno El Niño provocou grandes consequências em vários lugares do Brasil. Na Figura 07, nota-se que as anomalias da precipitação no período do evento climático apresenta uma grande variabilidade entre os próprios municípios, como por exemplo São Gabriel da Cachoeira no mês setembro de 2015 com uma anomalia -197,41 mm, esse baixo volume de formação de chuva é explicado principalmente pela influência do El Niño. No ano de 2016 a cidade de Manaus apresentou baixos níveis de formação de chuva de acordo Lopes e Pinto (2021) uma média de $44 \mathrm{~mm}$, este fato foi explicado pela influência do fenômeno El Niño, no qual provocou uma redução na precipitação. Marengo, et al., (2017) cita que em grande parte da região nordeste a seca entre os anos de 2012 a 2015 foi considerada uma das piores, devido a interferências das anomalias climáticas, acarretando assim prejuízos para agricultura, pecuária e principalmente para própria população que sofre com a falta d'água. Marengo e Souza Jr (2018) destacam que devido à seca associada a variabilidade natural dos eventos e alto índice de desmatamento provocou no ano de 2016 um número ainda maior de queimada. 
Figura 7. Anomalia da Precipitação em ano de El Niño 2015/2016.

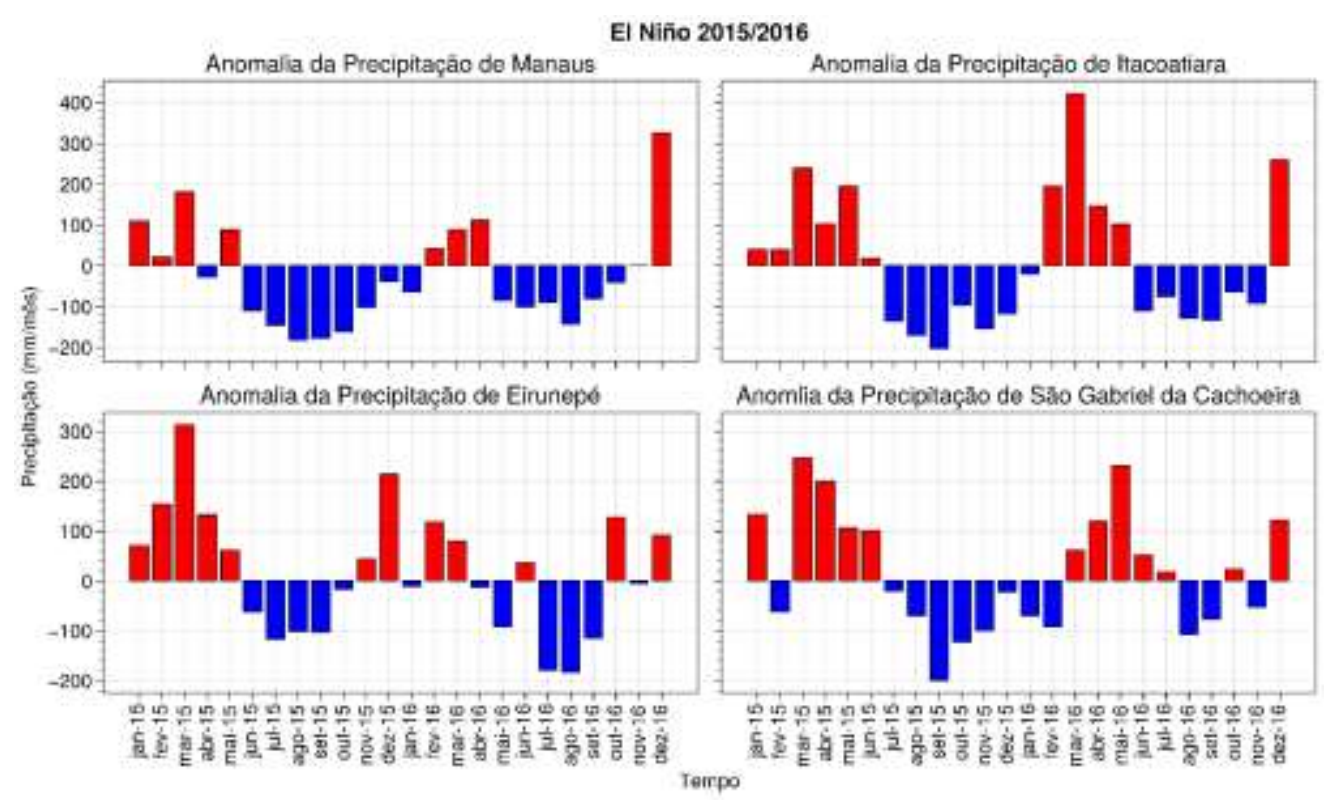

Fonte: Autores (2021).

Já os eventos de La Niña mais intensos (figura 3), verificou-se que dentre o período de estudo dos anos selecionados o ENSOS na sua fase fria mostrou maior intensidade nos anos de 1999-2000, 2007-2008. Os episódios de La Niña provocaram diferentes alterações variando de acordo com sua localidade, caracterizando uma intensificação dos ventos alísios e provocando chuvas abundantes na parte norte leste da Amazônia. As anomalias de precipitação são perceptíveis principalmente na estação chuvosa da Amazônia, onde provocam chuvas abundantes (De Freitas Moreira, et al., 2018), por este motivo observamos nos gráficos maiores níveis de precipitação entre dezembro e março, na qual é caracterizado como período chuvoso para região. Na cidade de Manaus (figura 8), verificamos no mês de maio 1999 um valor de 250 mm acima da média e no ano seguinte no mês de abril 2000 uma precipitação de $340 \mathrm{~mm}$ acima da média histórica, realçando assim a influência do evento La Niña nas chuvas na capital do Amazonas.

Figura 8. Anomalia da Precipitação em ano de La Niña 1999/2000.

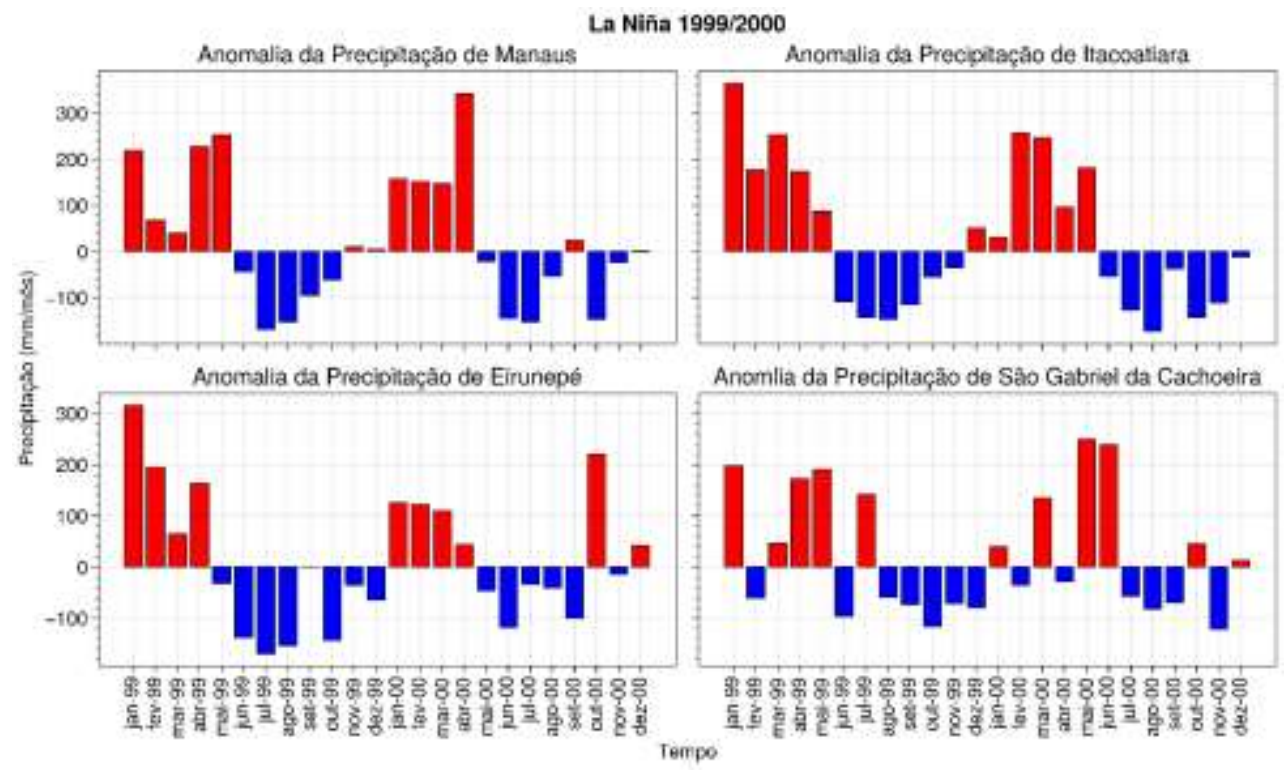

Fonte: Autores (2021). 
Pode-se observar na Figura 9 que o ano de 2007 apresentou máximas anomalias de precipitação principalmente no mês de fevereiro em todos municípios, isso se deve a fase de pico do período que se inicia uma fase fria (La Niña) apresentando fortes influências em 2008 a partir do mês de janeiro, assim também o mesmo ocorreu no estado do Amapá no ano de 2007, para o mês de março as precipitações apresentaram um aumeto chegando ao valor de $400 \mathrm{~mm} / \mathrm{mês} \mathrm{e} \mathrm{abrangendo}$ toda a faixa litorânea da região (Neves, et al., 2011). O aumento das precipitações também influenciam no aumento do regime fluvial dos rios na bacia Amazônica brasileira, Coutinho, et al.,

(2018) relatam durante o período de 1982-2012 o evento de La Niña provocou uma influência nas cheias em parte norte da bacia da Amazônica, assim como, na parte do Rio Tapajós e Xingu quando a mesma se fortalece provocando cheias.

Figura 9. Anomalia da Precipitação em ano de La Niña 2007/2008.

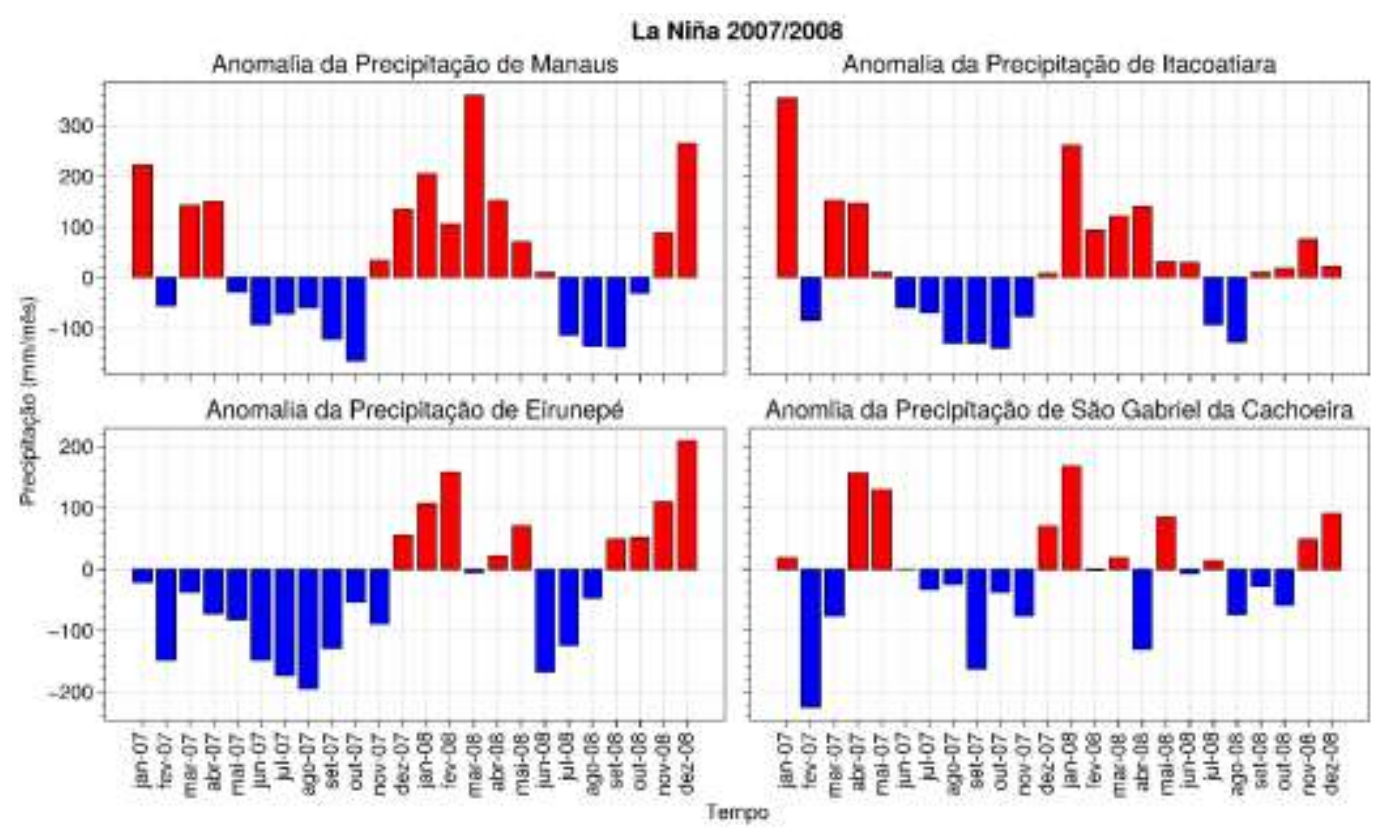

Fonte: Autores (2021).

\section{Conclusão}

Com este estudo verificou-se que nos anos de 1998, 2007 e 2016 apresentaram anomalias significativas com a presença dos eventos de El Niño e La Niña, o conhecimentos dos elementos climáticos, seja precipitação, temperatura ou pressão atmosférica relacionados com os fenômeno oceano- atmosférico ,nos proporciona uma melhor visibilidade de suas variabilidade e como os mesmo afetam a todo nosso sistema socioeconômico de uma região, influenciando diretamente no estado do Amazonas nas cheias e vazantes dos rios, ocasionando problemas sociais para comunidades ribeirinhas, como por exemplo, reduzindo atividade pesqueira e locomoção dos moradores, assim como nas cidades citadas formando altos níveis de precipitação e logo provocando enchentes, ou redução hídrica, por este motivo é necessário expandir o estudo para toda a região do estado do Amazonas, abrangendo todos seus municípios para prevenir futuras malezas, já que é de conhecimento que fenômenos climáticos oriundo do oceano pacifico influenciam de forma direta na precipitação no estado.

\section{Referências}

Albuquerque, M. F. D., Souza, E. B. D., Oliveira, M. D. C. F. D., \& Souza JúnioAlr, J. A. D. (2010). Precipitação nas mesorregiões do estado do Pará: climatologia, variabilidade e tendências nas últimas décadas (1978-2008).doi: doi: http://dx.doi.org/10.5380/abclima.v6i0.25606

Aleixo, N. C. R., \& Neto, J. C. A. D. S. (2019). Anos-padrão e tendências da precipitação pluvial na região do Médio Solimões, Amazonas, Brasil. Confins. Revue franco-brésilienne de géographie/Revista franco-brasilera de geografia, (43). doi: https://doi.org/10.4000/confins.25065 
Andreoli, R. V., \& Kayano, M. T. (2007). A importância relativa do Atlântico Tropical Sul e Pacífico Leste na variabilidade de precipitação do Nordeste do Brasil. Revista Brasileira de Meteorologia, 22, 63-74.doi: https://doi.org/10.1590/S0102-77862007000100007

Britto, F. P., \& Saraiva, J. M. B. (2001). Estudo da precipitação associada aos sistemas frontais na cidade do Rio Grande na estação do inverno. Geografia em Atos (Online), 1(3), 111-123.doi: http://dx.doi.org/10.35416/geoatos.v1i3.7607

Carvalho, D. F., \& Da Silva, L.D.B. (2006). Hidrologia: Capítulo 4. Precipitação.

Coutinho, E. D. C., Rocha, E. D., Lima, A. M. M., Ribeiro, H. M. C., Gutierrez, L. A. C. L., Barbosa, A. J. S., \& Tavares, P. A. (2018). Variabilidade climática da precipitação na bacia amazônica brasileira entre 1982 e 2012. Revista Brasileira de Climatologia, 22, 476-500.doi: https://doi.org/10.5380/abclima.v22i0

CPTEC - Centro de Previsão de Tempo e Estudos Climáticos. (2021). Brasil, 2021. El Niño http://enos.cptec.inpe.br/elnino/pt

Freitas Moreira, S., da Conceição, C. S., da Cruz, M. C. S., \& Júnior, A. P. (2018). A Influência dos fenômenos El Niño e La Niña sobre a dinâmica climática da região Amazônica. Multidisciplinary Reviews, 1, e2018014-e2018014. doi: https://doi.org/10.29327/multi.2018014

Morais Dias, G. F., Gomes, D. J. C., de Oliveira Serrão, E. A., de Lima, A. M. M., de Miranda, S. B. D. A., Júnior, J. D. A. S., \& de Souza, A. M. L. (2020). Associação entre os eventos de Enos e a distribuição espaço-temporal da precipitação na bacia hidrográfica do rio capim (MA-PA). Revista Brasileira de Climatologia, 26. doi: http://dx.doi.org/10.5380/abclima.v26i0.59320

Oliveira, B. L. F., Alves, L. G. S., de Carvalho, J. L. G., de Oliveira, D. G., \& da Silva, J. S. (2019). A seca de 2018 no alto rio negro e os impactos a população. Brazilian Journal of Development, 5(8), 11870-11879. doi:10.34117/bjdv5n8-048

Oliveira, R. N., \& Saraiva, J. M. B. (2018). Variabilidade da chuva na região central do amazonas: o uso do satélite TRMM. Revista geonorte, 9(33), 251-255. doi: https://doi.org/10.21170/geonorte.2018.V.9.N.33.251.255

Dorneles, V. R., Riquetti, N. B., \& Nunes, A. (2020). Forçantes dinâmicas e térmicas associadas a um caso de precipitação intensa sobre o Rio Grande do Sul, Brasil. Revista Brasileira de Climatologia, 26. doi: http://dx.doi.org/10.5380/abclima.v26i0.58162

Fisch, G., Marengo, J. A, \& Nobre, C. A. (1998). Uma revisão geral sobre o clima da Amazônia. Acta amazônica, 28(2), 101-101. doi:https://doi.org/10.1590/1809-43921998282126

Ggweather. (2021). El Niño and La Niña Years and Intensities https://ggweather.com/enso/oni.htm

GPCC- (2021). Global Precipitation Climatology Centre- Precipitation. https://psl.noaa.gov/data/gridded/data.gpcc.htm

Ibge. (2021). Cidades e Estados https://www.ibge.gov.br/cidades-e-estados/am.html

Inmet. (2021). Banco de Dados Meteorológicos do INMET https://bdmep.inmet.gov.br/

Júnior, A. L. P., Querino, C. A. S., da Silva Querino, J. K. A., dos Santos, L. O. F., de Mello Moura, A. R., Machado, N. G., \& Biurdes, M. S. (2018). Variabilidade horária e intensidade sazonal da precipitação no município de Humaitá-AM. Revista brasileira de Climatologia,22. doi: https://doi.org/10.5380/abclima.v22i0.58089

Lopes, A. B., \& Pinto, F. R. (2021). Made in Amazônia: Os elementos climáticos na cidade de manaus, am. Brasil: Atena Editora.

Marengo, J. A., \& Souza Jr, C. (2018). Mudanças Climáticas: impactos e cenários para a Amazônia. São Paulo

Marengo, J. A., Alves, L. M., Alvala, R., Cunha, A. P., Brito, S., \& Moraes, O. L. (2017). Climatic characteristics of the 2010-2016 drought in the semiarid Northeast Brazil region. Anais da Academia Brasileira de Ciências, 90, 1973-1985.doi: https://doi.org/10.1590/0001-3765201720170206

Mendonça, F., \& Danni-oliveira, I. M. Climatologia: noções básicas e climas do Brasil. São Paulo: Oficina de Texto, 2007.

Neves, D. G. D., Cunha, A. C. D., Souza, E. B. D., \& Barreto, N. J. D. C. (2011). Modelagem climática regional durante dois anos de extremos de Precipitação sobre o estado do amapá: teste de sensibilidade aos Esquemas convectivos. Revista Brasileira de Meteorologia, 26, 569-578.doi: https://doi.org/10.1590/S0102-77862011000400007

Oliveira, F. N. M. D., Araújo, R. L. C. D., Carvalho, J. D. S., \& Silva, C. L. D. (2006). Inferência de mudanças climáticas na região de Manaus (AM) usando dados geotermais e meteorológicos. Revista Brasileira de Geofísica, 24(2), 169-187.doi: https://doi.org/10.1590/S0102-261X2006000200002

Pereira, A. R., Angelocci, L. R., \& Sentelhas, P. C. (2002). Agrometeorologia: fundamentos e aplicações práticas. Guaíba: Agropecuaria.

Reboita, M. S., Krusche, N., Ambrizzi, T., \& Rocha, R. P. D. (2012). Entendendo o Tempo e o Clima na América do Sul. TERRAE DIDATICA ,8(1),34-50. doi: https://doi.org/10.20396/td.v8i1.8637425

Santos, J. G. M. D., Campos, C. R. J. D., \& Lima, K. C. (2008). Análise de jatos de baixos níveis associados a um sistema convectivo de mesoescala na américa do sul: um estudo de caso. Revista Brasileira de Geofísica, 26, 451-468.doi: https://doi.org/10.1590/S0102-261X2008000400006

Vargas, F. F., \& Veiga, J. A. P. (2017). Padrões atmosféricos e oceânicos associados a eventos secos na bacia amazônica nos anos de 1982/83, 2004/05 e 2009/10. Ciência e Natura, 39(2), 423-435.doi: https://doi.org/10.5902/2179460X22687

Vianello, R. L., \& Alves, A.R. (2012). Meteorologia básica e aplicações. Editora UFV.

Welter, V. (2018). Precipitação em verões sob influência de eventos ENOS canônico e Modoki no sudeste da América do Sul. http://tede.unioeste.br/handle/tede/4152 